\title{
Long-Term Aftereffects of Response Inhibition: Memory Retrieval, Task Goals, and Cognitive Control
}

\author{
Frederick Verbruggen \\ Vanderbilt University and Ghent University
}

Gordon D. Logan
Vanderbilt University

\begin{abstract}
Cognitive control theories attribute control to executive processes that adjust and control behavior online. Theories of automaticity attribute control to memory retrieval. In the present study, online adjustments and memory retrieval were examined, and their roles in controlling performance in the stop-signal paradigm were elucidated. There was evidence of short-term response time adjustments after unsuccessful stopping. In addition, it was found that memory retrieval can slow responses for 1-20 trials after successful inhibition, which suggests the automatic retrieval of task goals. On the basis of these findings, the authors concluded that cognitive control can rely on both memory retrieval and executive processes.
\end{abstract}

Keywords: stop-signal paradigm, executive control, task goals, memory retrieval, long-term priming

The role of goals in the control of behavior was a point of major controversy in the cognitive revolution against the behaviorists in the 1950s. Modern cognitive neuroscience approaches attribute control to executive processes that adjust behavior online in response to errors, conflict, or changes in the task environment (e.g., Botvinick, Braver, Barch, Carter, \& Cohen, 2001). Behaviorist approaches (e.g., Skinner, 1938) attribute control to environmental contingencies learned from experience. The behaviorist approach is echoed in cognitive theories of automaticity, which attribute control of skilled behavior to memory retrieval (e.g., Logan, 1988). In the present study, we investigated how memory retrieval and executive processes jointly control performance in the stop-signal paradigm (Logan \& Cowan, 1984; Vince, 1948).

The stop-signal paradigm is a popular tool for investigating response inhibition in cognitive science, cognitive neuroscience, lifespan development, psychopathology, and individual differences (for reviews, see Boucher, Palmeri, Logan, \& Schall, 2007; Logan, 1994). In this paradigm, subjects perform a choice reaction task (the primary task), and on a random selection of the trials, a stop signal instructs subjects to withhold their response. Performance depends on the relative finishing time of two processes: a go process, triggered by the presentation of the primary-task stimulus, and a stop process, triggered by the presentation of the stop signal. If the stop process finishes before the go process, subjects inhibit their response (signal-inhibit trials). If the go process fin-

Frederick Verbruggen, Department of Psychology, Vanderbilt University; and Department of Experimental Psychology, Ghent University, Ghent, Belgium; Gordon D. Logan, Department of Psychology, Vanderbilt University.

This research was supported by grants from the Research FoundationFlanders, Brussels, Belgium to Frederick Verbruggen and by National Science Foundation Grant BCS 0446806 and Air Force Office of Scientific Research Grant FA9550-07-1-0192 awarded to Gordon D. Logan. We thank Guido Band for comments on a previous version of this article.

Correspondence concerning this article should be addressed to Frederick Verbruggen, Department of Psychology, Vanderbilt University, Nashville, TN 37203. E-mail: frederick.verbruggen@ vanderbilt.edu ishes before the stop process, response inhibition fails and subjects respond (signal-respond trials). Response inhibition is widely accepted as an executive act of control (Logan, 1994). In the present study, we were concerned with further acts of control that follow response inhibition.

Several studies have shown slower responses following response inhibition on the immediately preceding trial, and researchers have interpreted the slowing as evidence for response time (RT) adjustments (Emeric et al., 2007; Rieger \& Gauggel, 1999). Executive processes could increase the response threshold, which would slow the finishing time of the go process and increase the probability of stopping. This idea elaborates the hypothesis that executive processes are involved in cognitively demanding situations, especially after the detection of a choice error or conflict between responses (e.g., Botvinick et al., 2001; Rabbitt, 1966). However, post-stop-signal slowing is greater when the primarytask stimulus is repeated (Rieger \& Gauggel, 1999; Verbruggen, Logan, Liefooghe, \& Vandierendonck, 2008), which suggests a memory-retrieval interpretation: When the stimulus repeats, the stop goal that was associated with it on the previous presentation is retrieved, and the stop goal activates the stop process, slowing the response to the repeated stimulus (Verbruggen et al., 2008). However, it remains unclear whether the stimulus-goal associations are temporary bindings or whether they are stored into memory in the form of long-term associations (Hommel, 2000; Logan, 1988). Researchers studying postsignal slowing have used only small sets of frequently repeated stimuli; therefore, they have not been able to distinguish between these two possibilities.

In the present study, we investigated the role of RT adjustments and memory retrieval in controlling goal-directed behavior in the stop-signal paradigm. The primary task was a semantic judgment in which subjects decided whether a word represented a living or a nonliving object. Each word was only presented once or twice, and a random selection of the words was repeated after a variable number of trials (i.e., lag; see Figure 1). We used four different lags: Lag 1 (i.e., the word from trial $n$ was repeated on trial $n+1$ ), Lag 5 (i.e., the word from trial $n$ was repeated on trial $n+5$ ), Lag 10 (i.e., the word from trial $n$ was repeated on trial $n+10$ ), and 


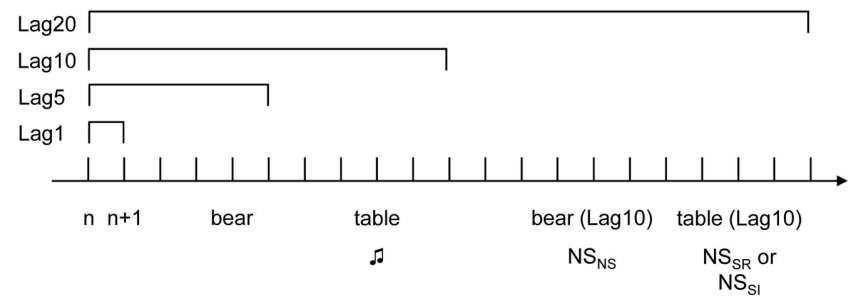

Figure 1. Trial course with the four lags (Lag 1, Lag 5, Lag 10, or Lag 20) used in the present study. The examples of the bear and the table are both stimulus repetitions at Lag 10. In the example of the table, a stop signal-represented by a musical note-is presented on the first presentation of the stimulus. Response inhibition could have succeeded $\left(\mathrm{NS}_{\mathrm{SI}}\right)$ or not $\left(\mathrm{NS}_{\mathrm{SR}}\right) \cdot \mathrm{n}=$ trial $n ; \mathrm{n}+1=$ trial $n+1$.

Lag 20 (i.e., the word from trial $n$ was repeated on trial $n+20$ ). The remaining words were used as fillers and were presented in random order with the restriction that each stimulus was presented twice at most. Filler repetitions were not further analyzed. On one third of the trials, a stop signal occurred, and we investigated the effect of the stop signal on the first presentation of a word. In contrast with previous studies, our lag manipulation allowed us to examine short-term and long-term aftereffects of response inhibition. We tested the short-term aftereffects of stopping by analyzing no-signal performance at Lag 1 . We tested the long-term aftereffects of stopping by analyzing no-signal performance at Lags $1-20$.

We distinguished between RT adjustments and memory retrieval and assumed that RT adjustments are short-term and not stimulus specific, whereas memory-retrieval effects are long-term and specific to particular stimuli. When testing the RT adjustment hypothesis, we distinguished between the signal for control adjustments and the control adjustments themselves (Botvinick et al., 2001). We assumed that RT adjustments are made by increasing the response threshold to increase the probability of stopping on signal trials. Such threshold adjustments prolong RT and increase accuracy on no-signal trials because more perceptual evidence is required to reach the response threshold (e.g., Rabbitt, 1966; Ratcliff, 1978).

We hypothesized two possible signals for RT adjustments:

Hypothesis 1: If stop signal then adjust. This hypothesis posits that RT adjustments are made after all stop trials to change the balance between the stop task and go task (Rieger \& Gauggel, 1999) or to reduce conflict between the stop and go processes (Emeric et al., 2007).

Hypothesis 2: If signal-respond then adjust. This hypothesis posits that RT adjustments are made only when response inhibition fails (Schachar et al., 2004; Verbruggen, Liefooghe, \& Vandierendonck, 2005; Verbruggen et al., 2008) to reduce failures to stop on the next trial. This hypothesis is consistent with the idea that control adjustments are made when the outcome on a trial differs from the expected outcome (see, e.g., Rabbitt, 1966).

We tested these predictions by comparing primary-task performance on no-signal trials that were preceded by a no-signal trial
$\left(\mathrm{NS}_{\mathrm{NS}}\right)$, a signal-respond trial $\left(\mathrm{NS}_{\mathrm{SR}}\right)$, or a signal-inhibit trial $\left(\mathrm{NS}_{\mathrm{SI}}\right)$. The if stop signal then adjust hypothesis predicts longer primary-task RT on $\mathrm{NS}_{\mathrm{SI}}$ and $\mathrm{NS}_{\mathrm{SR}}$ trials than on $\mathrm{NS}_{\mathrm{NS}}$ trials (i.e., $\left.\mathrm{NS}_{\mathrm{NS}}<\mathrm{NS}_{\mathrm{SI}}=\mathrm{NS}_{\mathrm{SR}}\right)$. Similarly, the hypothesis predicts lower error percentages on $\mathrm{NS}_{\mathrm{SI}}$ and $\mathrm{NS}_{\mathrm{SR}}$ trials than on $\mathrm{NS}_{\mathrm{NS}}$ trials. Note that Emeric et al. (2007) hypothesized that the greater the conflict, the greater the slowing after stop-signal trials. At this point, we assume that the degree of conflict will be approximately the same for $\mathrm{NS}_{\mathrm{SI}}$ and $\mathrm{NS}_{\mathrm{SR}}$ trials in the stop-signal paradigm. The if signal-respond then adjust hypothesis predicts longer primarytask RT on $\mathrm{NS}_{\mathrm{SR}}$ trials than on $\mathrm{NS}_{\mathrm{NS}}$ and $\mathrm{NS}_{\mathrm{SI}}$ trials (i.e., $\mathrm{NS}_{\mathrm{NS}}=$ $\mathrm{NS}_{\mathrm{SI}}<\mathrm{NS}_{\mathrm{SR}}$ ) and lower error percentages on $\mathrm{NS}_{\mathrm{SR}}$ trials than on $\mathrm{NS}_{\mathrm{NS}}$ and $\mathrm{NS}_{\mathrm{SI}}$ trials.

We assume that RT adjustments are made after the signal trial and before the following no-signal trial. Consequently, RT adjustments should occur whether or not the primary-task stimulus of the previous signal trial is repeated. However, when the primary-task stimulus repeats (i.e., stimulus-repetition trials), both memory retrieval and RT adjustments could contribute to the aftereffects of stopping (Rieger \& Gauggel, 1999; Verbruggen et al., 2008). By contrast, when the stimulus- and response-repetition effects are excluded (i.e., no-repetition trials), aftereffects of stopping are due to RT adjustments only (for similar ideas, see, e.g., Kerns et al., 2004; Verbruggen, Notebaert, Liefooghe, \& Vandierendonck, 2006). Therefore, we analyzed performance on no-repetition trials to distinguish between the two RT adjustment hypotheses.

We tested the memory-retrieval effects by analyzing short-term (Lag 1) and long-term (Lags 5-20) aftereffects of stopping on stimulus-repetition trials. We argue on the basis of the instance theory of automaticity (Logan, 1988) that a stop goal is associated with the primary-task stimulus whenever a stop signal is presented, and the stop goal is retrieved when the stimulus is repeated. The retrieved stop goal activates the stop process, and this slows the go response if there is no stop signal on the current trial. This memory-retrieval hypothesis predicts that $\mathrm{NS}_{\mathrm{NS}} \mathrm{RT} \leq \mathrm{NS}_{\mathrm{SR}} \mathrm{RT}<$ $\mathrm{NS}_{\mathrm{SI}} \mathrm{RT}$, but only on stimulus-repetition trials. We predicted that the stimulus-stop association-and therefore, the slowing-would depend on the outcome of the stop process on the first presentation. We assumed that the association would be strong on signal-inhibit trials, on which the stop goal is activated and the stop process succeeds; thus, $\mathrm{NS}_{\mathrm{SI}}>\mathrm{NS}_{\mathrm{NS}}$. We assumed that the association would be weaker on signal-respond trials in which the stop goal is activated but not strongly enough to inhibit the go response; therefore, $\mathrm{NS}_{\mathrm{SR}}>\mathrm{NS}_{\mathrm{NS}}$. Furthermore, the association might not be made at all on signal-respond trials in which the response is executed before the stop goal is activated, therefore $\mathrm{NS}_{\mathrm{SR}}=\mathrm{NS}_{\mathrm{NS}}$.

For all trial types, memory-retrieval effects are assumed to be strongest at Lag 1 and weaker but still significant at longer lags (Grant \& Logan, 1993), whereas temporary bindings should only affect performance at Lag 1 . The memory-retrieval hypothesis does not make predictions about error percentages. To test the memory-retrieval hypothesis, we analyzed stimulus-repetition trials as a function of lag between the first and second presentation.

\section{Method}

\section{Subjects}

Twenty-four students from Vanderbilt University participated for course credit. Eight subjects were replaced because accuracy 
was below $70 \%$ in one of the conditions. The RT data pattern was not altered by the exclusion of these subjects.

\section{Apparatus and Stimuli}

The experiment was run on a PC running Tscope (Stevens, Lammertyn, Verbruggen, \& Vandierendonck, 2006), and the stimuli were presented on a 21-in. (533-mm) monitor. Subjects made living-nonliving judgments about the referents of words. For each subject, a random subset of 520 words was drawn from a list of 640 words used by Arrington and Logan (2004). In the practice phase, another subset of 30 target words was drawn. The target words were presented in white lowercase Courier font (18 point) on a black background. The targets appeared between two white vertical lines ( $6 \mathrm{~mm}$ in length; the distance between the two lines was $12 \mathrm{~mm}$ ). Subjects responded by pressing the $x$ key ("living") with the left index finger or the $n$ key ("nonliving") with the right index finger. On some trials, an auditory tone (pitch, $750 \mathrm{~Hz}$; duration, $75 \mathrm{~ms}$; sound level, $80 \mathrm{~dB}$ ) was presented through speakers placed next to the screen.

\section{Procedure}

Instructions emphasized both accuracy and speed. All trials began with the presentation of the two vertical lines, and the target word appeared after $250 \mathrm{~ms}$. The target and the lines remained on the screen until subjects responded or 1,500 ms elapsed. The next trial started after $750 \mathrm{~ms}$. The experiment started with one practice block of 30 trials. The experimental phase consisted of eight blocks of 120 trials.

On one third of the trials, an auditory tone was presented that indicated that subjects were to stop their response. Stop-signal delay (SSD) was initially set at $250 \mathrm{~ms}$, and we continuously adjusted it with a tracking procedure to obtain a probability of stopping of .50. SSD decreased by $50 \mathrm{~ms}$ after a signal-respond trial, and SSD increased by $50 \mathrm{~ms}$ after a signal-inhibit trial. Subjects were told not to wait for the stop signal.

The presentation of targets and stop signals was pseudorandomized for each subject, and each stimulus was presented twice at most. A random selection of the targets for both no-signal and signal trials repeated after a variable lag (Lag 1, Lag 5, Lag 10, or Lag 20). The remaining targets were presented in random order.

\section{Results}

Mean RT of correct no-signal trials and accuracy data was calculated after the exclusion of (a) Lag 5, Lag 10, or Lag 20 trials that were immediately preceded by a stop signal, (b) trials that were preceded by a stop signal on trial $n-2$, (c) trials that were preceded by a choice error (i.e., the erroneous response to the word), and (d) repetitions that occurred between blocks. Forty-two percent of the stimulus-repetition trials were rejected after the application of these exclusion criteria.

Mean probability of stopping on stop-signal trials was .49 $(S D=.006)$, and mean SSD was $500 \mathrm{~ms}(S D=90 \mathrm{~ms})$. Stopsignal reaction time, which we calculated by subtracting mean SSD from mean RT of all trials (Logan, Schachar, \& Tannock, 1997), was $201 \mathrm{~ms}(S D=39 \mathrm{~ms})$.

\section{RT Adjustments}

To examine RT adjustments, we submitted RT and error data from $\mathrm{NS}_{\mathrm{NS}}, \mathrm{NS}_{\mathrm{SR}}$, and $\mathrm{NS}_{\mathrm{SI}}$ no-repetition trials (i.e., trials in which the stimulus is presented for the first time and the expected response is different from the expected response from trial $n-1)^{1}$ to separate analyses of variance (ANOVAs) with signal properties of trial $n-1$ (no-signal, signal-respond, or signal-inhibit) as within-subject factors. For each subject, there were at least five observations in each cell of the data matrix (average number of observations: $\mathrm{NS}_{\mathrm{SR}}=12, \mathrm{NS}_{\mathrm{SI}}=11, \mathrm{NS}_{\mathrm{NS}}=41$ ). In this analysis (and in all other analyses that follow) we conducted planned comparisons, using the relevant error terms from the omnibus ANOVA.

For RT data, we found a main effect of signal properties of trial $n-1, F(2,46)=13.5, M S E=1,985, p<.001, \eta_{\mathrm{p}}^{2}=.37$, which suggests that subjects made RT adjustments. Planned comparisons showed that $\mathrm{NS}_{\mathrm{SR}} \mathrm{RT}(809 \mathrm{~ms})$ was longer than $\mathrm{NS}_{\mathrm{NS}} \mathrm{RT}$ (747 $\mathrm{ms})$ and $\mathrm{NS}_{\mathrm{SI}} \mathrm{RT}(756 \mathrm{~ms}), F(1,46)=23.1, p<.001, \eta_{\mathrm{p}}^{2}=.33$ and, $F(1,46)=17.0, p<.001, \eta_{\mathrm{p}}^{2}=.27$. There was no difference between $\mathrm{NS}_{\mathrm{NS}} \mathrm{RT}$ and $\mathrm{NS}_{\mathrm{SI}} \mathrm{RT}(F<1)$. This finding suggests that subjects made RT adjustments after unsuccessful inhibition but not after successful inhibition. For the accuracy data, the main effect was nonsignificant $(F<1)$. Accuracy was comparable for $\mathrm{NS}_{\mathrm{SR}}$ $(90.7 \%), \mathrm{NS}_{\mathrm{NS}}(90.6 \%)$, and $\mathrm{NS}_{\mathrm{SI}}$ trials $(90.3 \%)$.

The if stop signal then adjust hypothesis predicted $\mathrm{NS}_{\mathrm{NS}}<$ $\mathrm{NS}_{\mathrm{SI}}=\mathrm{NS}_{\mathrm{SR}} \mathrm{RT}$, whereas the if signal-respond then adjust hypothesis predicted $\mathrm{NS}_{\mathrm{NS}}=\mathrm{NS}_{\mathrm{SI}}<\mathrm{NS}_{\mathrm{SR}} \mathrm{RT}$. The RT data are consistent with the if signal-respond then adjust hypothesis, suggesting that subjects traded speed in the primary task for success in the stop task after unsuccessful stopping. However, we did not find an effect of trial $n-1$ for the accuracy data, even though both RT adjustment hypotheses predicted that accuracy should increase with increasing RT. One could speculate that after unsuccessful stopping, subjects do not increase the response threshold but postpone processing the primary-task stimulus. In this case, the same amount of perceptual evidence is needed to reach the threshold, which explains why RT but not accuracy is increased.

\section{Memory Retrieval}

To examine memory retrieval, RT, and accuracy, we submitted data from $\mathrm{NS}_{\mathrm{NS}}, \mathrm{NS}_{\mathrm{SR}}$, and $\mathrm{NS}_{\mathrm{SI}}$ stimulus-repetition trials to separate repeated measures ANOVAs with signal properties of the

\footnotetext{
${ }^{1}$ For Lag 1 , we also analyzed first-presentation trials on which the stimulus category and expected response of trial $n-1$ were repeated. Separate ANOVAs showed that $\mathrm{NS}_{\mathrm{NS}} \mathrm{RT}(717 \mathrm{~ms})$ was shorter than $\mathrm{NS}_{\mathrm{SR}}$ $\mathrm{RT}(775 \mathrm{~ms}), F(1,23)=11.7, M S E=3,470, p<.01, \eta_{\mathrm{p}}^{2}=.34$, and $\mathrm{NS}_{\mathrm{SI}}$ RT $(787 \mathrm{~ms}), F(1,23)=34.3, M S E=1,738, p<.001, \eta_{\mathrm{p}}^{2}=.60$. The difference between $\mathrm{NS}_{\mathrm{SR}}$ RT and $\mathrm{NS}_{\mathrm{SI}}$ RT was nonsignificant, $F<1$. Because we did not find evidence for RT adjustments after no-repetition signal-inhibit trials, these results suggest memory-retrieval effects when the stimulus-category was repeated. However, these effects are less pronounced than those found after stimulus-repetition trials (see also Verbruggen et al., 2008), which explains why there is no difference between $\mathrm{NS}_{\mathrm{SR}}$ $\mathrm{RT}$ (viz., slowing due to RT adjustments) and $\mathrm{NS}_{\mathrm{SI}} \mathrm{RT}$ (viz., slowing due to memory retrieval). For the accuracy data, all differences were nonsignificant (all $p \mathrm{~s}>.31$ ), which suggests that accuracy was comparable for $\mathrm{NS}_{\mathrm{NS}}(92.5 \%), \mathrm{NS}_{\mathrm{SR}}(91.3 \%)$, and $\mathrm{NS}_{\mathrm{SI}}(93.5 \%)$ trials.
} 
first presentation (no-signal, signal-respond, or signal-inhibit) and lag (Lag 1, Lag 5, Lag 10, Lag 20) as within-subject factors. For each subject, there were at least seven observations in each cell of the data matrix (average number of observations, $\mathrm{NS}_{\mathrm{SR}}=18$, $\mathrm{NS}_{\mathrm{SI}}=18, \mathrm{NS}_{\mathrm{NS}}=15$ ). $\mathrm{RT}$ and accuracy for no-signal trials are depicted in Figure 2. ANOVA results appear in Table 1.

As can be seen, the main effects of signal properties of the first presentation and lag were significant. For RT, the interaction between the two factors was also significant. The memoryretrieval hypothesis predicted that $\mathrm{NS}_{\mathrm{NS}} \leq \mathrm{NS}_{\mathrm{SR}}<\mathrm{NS}_{\mathrm{SI}} \mathrm{RT}$ for all lags. Therefore, we performed three specific planned comparisons for all lags: $\mathrm{NS}_{\mathrm{NS}}$ versus $\mathrm{NS}_{\mathrm{SR}}$ trials, $\mathrm{NS}_{\mathrm{NS}}$ versus $\mathrm{NS}_{\mathrm{SI}}$ trials, and $\mathrm{NS}_{\mathrm{SR}}$ versus $\mathrm{NS}_{\mathrm{SI}}$ trials (see Table 1).

First, the comparison of $\mathrm{NS}_{\mathrm{NS}}$ versus $\mathrm{NS}_{\mathrm{SR}}$ trials showed that $\mathrm{NS}_{\mathrm{NS}}$ RT (524 ms) was shorter than $\mathrm{NS}_{\mathrm{SR}} \mathrm{RT}$ (608 ms) for Lag 1. This is consistent with the no-repetition trial findings (see above). There were no differences in RT for the three other lags (see the left panel of Figure 2 and Table 1). This suggests that the aftereffects of unsuccessful stopping are mainly due to short-term RT adjustments (see above). Moreover, the absence of memoryretrieval effects suggests that the stop goal was not strongly associated with the stimulus on signal-respond trials. Accuracy was higher at Lag 20 for $\mathrm{NS}_{\mathrm{SR}}$ trials $(94.8 \%)$ than for $\mathrm{NS}_{\mathrm{NS}}$ trials (91.1\%). The differences for Lag 1, Lag 5, and Lag 10 were nonsignificant (see Table 1).

Second, the comparison of $\mathrm{NS}_{\mathrm{NS}}$ versus $\mathrm{NS}_{\mathrm{SI}}$ trials showed that $\mathrm{NS}_{\mathrm{NS}} \mathrm{RT}$ was shorter than $\mathrm{NS}_{\mathrm{SI}} \mathrm{RT}$ for Lag $1\left(\mathrm{NS}_{\mathrm{NS}}=524 \mathrm{~ms}\right.$, $\left.\mathrm{NS}_{\mathrm{SI}}=666 \mathrm{~ms}\right)$, Lag $5\left(\mathrm{NS}_{\mathrm{NS}}=675 \mathrm{~ms}, \mathrm{NS}_{\mathrm{SI}}=730 \mathrm{~ms}\right), \mathrm{Lag}$ $10\left(\mathrm{NS}_{\mathrm{NS}}=678 \mathrm{~ms}, \mathrm{NS}_{\mathrm{SI}}=710 \mathrm{~ms}\right)$, and Lag $20\left(\mathrm{NS}_{\mathrm{NS}}=680\right.$ $\left.\mathrm{ms}, \mathrm{NS}_{\mathrm{SI}}=716 \mathrm{~ms}\right)$. This finding is consistent with a memoryretrieval effect following successful inhibition on the first presentation. For accuracy, we found a significant difference for Lag 1 $\left(\mathrm{NS}_{\mathrm{NS}}=98.9 \%, \mathrm{NS}_{\mathrm{SI}}=92.8 \%\right)$. There were no differences for the other lags (see Table 1 and Figure 2).

Third, the comparison of $\mathrm{NS}_{\mathrm{SR}}$ versus $\mathrm{NS}_{\mathrm{SI}}$ trials showed that $\mathrm{NS}_{\mathrm{SR}} \mathrm{RT}$ was shorter than $\mathrm{NS}_{\mathrm{SI}} \mathrm{RT}$ for Lag $1\left(\mathrm{NS}_{\mathrm{SR}}=608 \mathrm{~ms}\right.$, $\left.\mathrm{NS}_{\mathrm{SI}}=666 \mathrm{~ms}\right)$, Lag $5\left(\mathrm{NS}_{\mathrm{SR}}=685 \mathrm{~ms}, \mathrm{NS}_{\mathrm{SI}}=730 \mathrm{~ms}\right), \mathrm{Lag}$
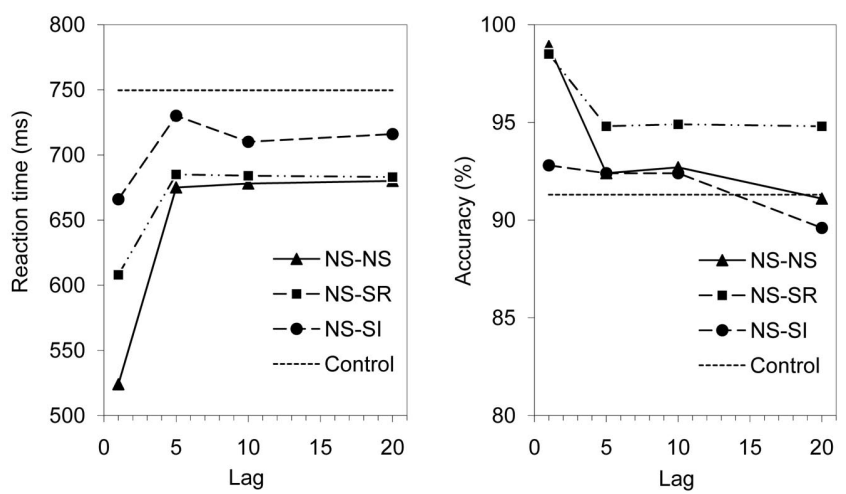

Figure 2. Mean reaction times (left) and error percentages (right) of stimulus-repetition trials are shown as a function of lag between the first and second presentation. The dotted lines represent the mean reaction time (left) and the mean error percentage (right) of control trials. NS-NS = no-signal trial preceded by a no-signal trial; NS-SR $=$ no-signal trial preceded by a signal-respond trial; NS-SI $=$ no-signal trial preceded by a signal-inhibit trial; Control $=$ control trials
$10\left(\mathrm{NS}_{\mathrm{SR}}=684 \mathrm{~ms}, \mathrm{NS}_{\mathrm{SI}}=710 \mathrm{~ms}\right)$, and Lag $20\left(\mathrm{NS}_{\mathrm{SR}}=683\right.$ $\left.\mathrm{ms}, \mathrm{NS}_{\mathrm{SI}}=716 \mathrm{~ms}\right)$. Once more, this finding suggests that the aftereffects of unsuccessful and successful stopping are different. For accuracy, we found a significant difference for Lag $1\left(\mathrm{NS}_{\mathrm{SR}}=\right.$ $\left.98.5 \%, \mathrm{NS}_{\mathrm{SI}}=92.8 \%\right)$ and $\mathrm{Lag} 20\left(\mathrm{NS}_{\mathrm{SR}}=94.8 \%, \mathrm{NS}_{\mathrm{SI}}=\right.$ 92.8\%). The differences for Lag 5 and Lag 10 were nonsignificant (see Table 1).

We also compared $\mathrm{NS}_{\mathrm{NS}}, \mathrm{NS}_{\mathrm{SR}}$, and $\mathrm{NS}_{\mathrm{SI}}$ RTs for Lag 20 with first-presentation control RTs by means of separate ANOVAs. The ANOVAs revealed that first-presentation control RTs $(750 \mathrm{~ms}$; the dotted line in Figure 2, left panel) were longer than $\mathrm{NS}_{\mathrm{NS}} \mathrm{RTs}$, $F(1,23)=52.7, \mathrm{MSE}=1,102, p<.001, \eta_{\mathrm{p}}^{2}=.70 ; \mathrm{NS}_{\mathrm{SR}} \mathrm{RTs}$, $F(1,23)=45.9, M S E=1,156, p<.001, \eta_{\mathrm{p}}^{2}=.67$; and $\mathrm{NS}_{\mathrm{SI}} \mathrm{RTs}$, $F(1,23)=8.8, M S E=1,508, p<.01, \eta_{\mathrm{p}}^{2}=.28$, which suggests long-term priming (Grant \& Logan, 1993). The repetition benefit on $\mathrm{NS}_{\mathrm{SI}}$ trials also suggests stimuli can be associated with interpretations even if the response is not executed (Logan, 1985).

\section{Discussion}

In the present study, we examined the role of RT adjustments and memory retrieval in controlling goal-directed behavior by testing short-term and long-term aftereffects of response inhibition. Consistent with previous studies, we found evidence for RT adjustments when repetition-priming effects were excluded. We found that RT slowed down after unsuccessful inhibition, although the slowing was not accompanied by a reduction in error rate. No such effects were found when response inhibition succeeded. These findings support the if signal-respond then adjust hypothesis, but future research is needed to investigate why the RT adjustments did not affect accuracy.

In addition, the long-term priming analyses revealed that memory retrieval can slow responses for 1 to 20 trials after successful inhibition. This suggests that the primary task stimulus was associated with the stop goal when the response was inhibited, and the stop goal was retrieved when the stimulus was presented a second time. The slowing after successful inhibition suggests memory retrieval and the automatic activation of the stop goal through direct stimulus-goal associations. We assume that when subjects successfully inhibit a response, the stimulus is associated with the stop goal (Logan, 1988). When the stimulus is repeated after a variable lag, the stop goal is retrieved and automatically activated, which suppresses the go response, even though there was no stop signal. This suppression can be understood in an interactive race model of countermanding performance (Boucher et al., 2007), in which a go process and a stop process are independent for much of the time they take to execute (see Figure 3). However, once the stop unit is activated (viz., the stop goal), it inhibits go processing strongly and quickly. In this model, stop-signal RT primarily reflects the period before the stop unit is activated, during which stop and go processing are independent (see Figure 3C); therefore its predictions approximate those of the independent race model (Logan \& Cowan, 1984). To account for the present results, we assume that the stop unit can be activated through the retrieval of previous associations with the go stimulus, which slows the rate at which evidence for the go response accumulates (see Figures 3B and 3D).

The absence of long-term priming after unsuccessful inhibition suggests that the primary-task stimulus was not associated 
Table 1

Analyses of Variance and F Values for Memory-Retrieval Effects

\begin{tabular}{|c|c|c|c|c|c|c|}
\hline \multirow[t]{3}{*}{ Variable } & \multicolumn{3}{|c|}{ RT } & \multicolumn{3}{|c|}{ Accuracy } \\
\hline & \multicolumn{6}{|c|}{ Global analyses } \\
\hline & $F$ & $d f$ & $\eta_{\mathrm{p}}^{2}$ & $F$ & $d f$ & $\eta_{\mathrm{p}}^{2}$ \\
\hline Signal & $30.2^{* * *}$ & 2,46 & .57 & $9.4^{* *}$ & 2,46 & .29 \\
\hline Lag & $48.5^{* *}$ & 3,69 & .68 & $8.9^{* *}$ & 3,69 & .28 \\
\hline Signal $\times$ Lag & $7.6^{* * *}$ & 6,138 & .25 & 1.6 & 6,138 & .06 \\
\hline
\end{tabular}

\begin{tabular}{lcccccccc} 
& Lag 1* & Lag 5 & Lag 10 & Lag 20 & Lag 1 & Lag 5 & Lag 10 & Lag 20 \\
NS $_{\mathrm{NS}}$ vs. NS & $36.8^{* *}$ & $<1$ & $<1$ & $<1$ & $<1$ & 1.9 & 1.6 & $4.5^{*}$ \\
NS $_{\mathrm{NS}}$ vs. NS & $105.1^{* *}$ & $15.6^{* * *}$ & $5.3^{*}$ & $6.9^{*}$ & $12.6^{* *}$ & $<1$ & $<1$ & $<1$ \\
NS $_{\mathrm{SR}}$ vs. NS & $17.5^{* *}$ & $10.6^{* *}$ & $3.6^{\dagger}$ & $5.8^{*}$ & $10.8^{* *}$ & 1.9 & 2.1 & $9.1^{* * *}$ \\
\hline
\end{tabular}

Note. $\quad \mathrm{NS}_{\mathrm{NS}}=$ no-signal trial preceded by a no-signal trial; $\mathrm{NS}_{\mathrm{SI}}=$ no signal trial preceded by a signal-inhibit trial; $\mathrm{NS}_{\mathrm{SR}}=$ no signal trial preceded by a signal-respond trial; $\mathrm{RT}=$ response time.

${ }^{\dagger} p=.06 .{ }^{*} p<.05 .{ }^{* *} p<.01$.

with the stop goal when inhibition was not successful. Thus, the association between the stimulus and the stop goal will be weaker on signal-respond trials than on signal-inhibit trials. However, it is also possible that subjects associate the stimulus with the goal they actually fulfilled (i.e., the go goal) and not with the goal they failed to fulfill (i.e., the stop goal). Our data do not allow us to distinguish between the two explanations.

The idea that the stimulus becomes associated with the stop goal resembles certain accounts of inhibitory aftereffects such as negative priming (Neill \& Valdes, 1992; Neill, Valdes, Terry, \&
A

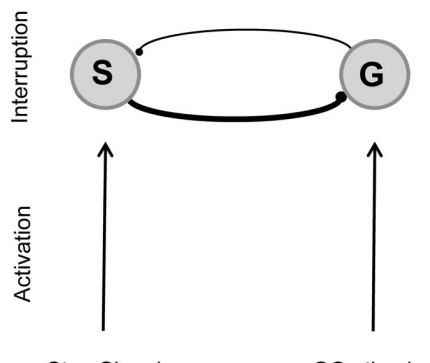

C

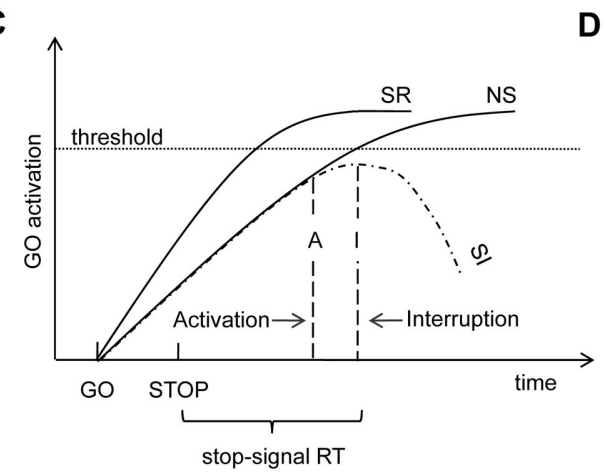

B

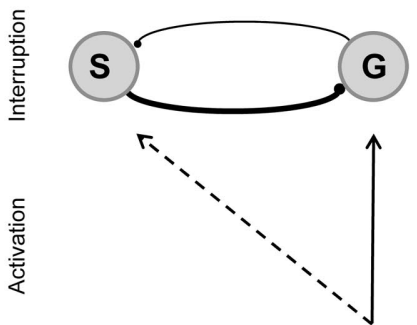

GO stimulus

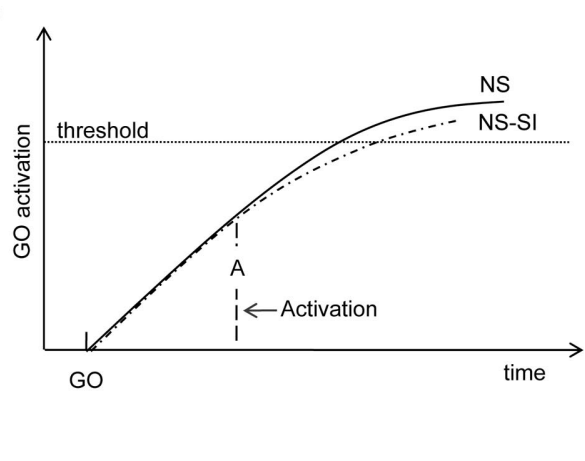

Figure 3. The interactive race model of performance. The moment the stop unit is activated (Panels C and D) is indicated by the left-most vertical dashed line (A); the moment go-processing is successfully interrupted (Panel C) is indicated by the right-most vertical dashed line (I). $\mathrm{S}=$ stop unit; $\mathrm{G}=$ go unit; $\mathrm{SR}=$ signal-respond trial; NS = no-signal trial; $\mathrm{SI}=$ signal-inhibit trial; NS-SI = no-signal trial preceded by a signal-inhibit trial; $\mathrm{RT}=$ reaction time . 
Gorfein, 1992) and long-term inhibition of return (Tipper, Grison, $\&$ Kessler, 2003). The key idea in these accounts is that a stimulus becomes associated with a "do not respond" tag or an inhibitory state that corresponds to the goal or subgoal of a processing episode (i.e., "do not attend or respond to object $x$ "). We make this idea concrete in our extension of the interactive race model (Boucher et al., 2007). The idea that stimuli become associated with goals (or with tasks or with task-specific responses) has also been used in the task-switching paradigm (e.g., Mayr \& Bryck, 2005; Waszak, Hommel, \& Allport, 2003). Those associations also have long-term effects on performance, which can last longer than 100 trials (Waszak et al., 2003).

More generally, memory retrieval may allow the environment to control behavior (Skinner, 1938) by activating goals associated with environmental stimuli (Ach, 1935; G. A. Miller, Galanter, \& Pribram, 1960). Associations between stimuli and stop goals may be prevalent in everyday life as people learn not to respond to certain stimuli. For example, people usually do not try to catch a cactus that is falling off of a desk or touch a hot burner on a stove. Thus, executive processes such as response inhibition may be triggered automatically by environmental stimuli.

The idea of memory-retrieval control may help explain differences between the stop-signal paradigm and the go/no-go paradigm, which are often viewed as similar measures of response inhibition (Rubia et al., 2001). In the go/no-go paradigm, subjects always respond to the go stimulus and never respond to the no-go stimulus. This consistent mapping of go stimuli onto go goals and no-go stimuli onto stop goals invites memory-retrieval control of response inhibition (Shiffrin \& Schneider, 1977). No endogenous response inhibition may be required. By contrast, in the stop-signal paradigm, stimuli are associated with the go goal on no-signal trials and with the stop goal on stop-signal trials. This inconsistent mapping of stimuli onto task goals implies that memory retrieval cannot be the only mechanism underlying response inhibition (Shiffrin \& Schneider, 1977). The novel contribution of our results shows that control by memory retrieval complements control by executive processes in the stop-signal paradigm.

Future research should establish how memory retrieval and executive processes work together to control performance. We propose an executive system that monitors performance and relies on feedback mechanisms, such as conflict detection, to produce rapid control adjustments whenever needed (Botvinick et al., 2001). On no-signal trials, input and feedback from lower systems indicate that no stop signal was presented so the go goal must be fulfilled. Such goal-related processes are thought to be the core of the executive control system, and they rely on brain regions such as the prefrontal cortex that exert executive control by maintaining patterns of activity that represent task goals and the means to achieve them (E. K. Miller \& Cohen, 2001). This executive system works in concert with automatic memory retrieval, which suggests courses of action that fulfill familiar goals (Logan, 1988). The executive system can choose to go with the flow of familiar memories or oppose them, depending on its higher level goals (also see Bargh \& Chartrand, 1999).

Cognitive control and automaticity are often regarded as opposites (Shiffrin \& Schneider, 1977). The present study suggests that cognitive control can rely on both memory retrieval and executive processes. Internal task goals can be automatically activated by a single instance, but when needed, they can be inhibited or replaced by an executive system.

\section{References}

Ach, N. (1935). Analyse des Willens [Analysis of the will]. In E. Abderhalden (Ed.), Handbuch der biologischen Arbeitsmethoden [Handbook of biological methods]. Berlin, Germany: Urban \& Schwarzenberg.

Arrington, C. M., \& Logan, G. D. (2004). Episodic and semantic components of the compound-stimulus strategy in the explicit task-cuing procedure. Memory \& Cognition, 32, 965-978.

Bargh, J. A., \& Chartrand, T. L. (1999). The unbearable automaticity of being. American Psychologist, 54, 462-479.

Botvinick, M. M., Braver, T. S., Barch, D. M., Carter, C. S., \& Cohen, J. D. (2001). Conflict monitoring and cognitive control. Psychological Review, 108, 624-652.

Boucher, L., Palmeri, T. J., Logan, G. D., \& Schall, J. D. (2007). Inhibitory control in mind and brain: An interactive race model of countermanding saccades. Psychological Review, 114, 376-397.

Emeric, E. E., Brown, J. W., Boucher, L., Carpenter, R. H. S., Hanes, D. P., Harris, R., et al. (2007). Influence of history on saccade countermanding performance in humans and macaque monkeys. Vision Research, 47, $35-49$.

Grant, S. C., \& Logan, G. D. (1993). The loss of repetition priming and automaticity over time as a function of degree of initial learning. Memory \& Cognition, 21, 611-618.

Hommel, B. (2000). The prepared reflex: Automaticity and control in stimulus-response translation. In S. Monsell \& J. Driver (Eds.), Control of cognitive processes: Attention and Performance XVIII (pp. 247-273). Cambridge, MA: MIT Press.

Kerns, J. G., Cohen, J. D., MacDonald, A. W., III, Cho, R. Y., Stenger, V. A., \& Carter, C. S. (2004, February 13). Anterior cingulate conflict monitoring and adjustments in control. Science, 303, 1023-1026.

Logan, G. D. (1985). On the ability to inhibit simple thoughts and actions: II. Stop-signal studies of repetition priming. Journal of Experimental Psychology: Learning, Memory, and Cognition, 11, 675-691.

Logan, G. D. (1988). Toward an instance theory of automatization. Psychological Review, 95, 492-527.

Logan, G. D. (1994). On the ability to inhibit thought and action: A user's guide to the stop signal paradigm. In D. Dagenbach \& T. H. Carr (Eds.), Inhibitory processes in attention, memory and language (pp. 189-239). San Diego, CA: Academic Press.

Logan, G. D., \& Cowan, W. B. (1984). On the ability to inhibit thought and action: A theory of an act of control. Psychological Review, 91, 295327.

Logan, G. D., Schachar, R. J., \& Tannock, R. (1997). Impulsivity and inhibitory control. Psychological Science, 8, 60-64.

Mayr, U., \& Bryck, R. L. (2005). Sticky rules: Integration between abstract rules and specific actions. Journal of Experimental Psychology: Learning, Memory, and Cognition, 31, 337-350.

Miller, E. K., \& Cohen, J. D. (2001). An integrative theory of prefrontal cortex function. Annual Review of Neuroscience, 24, 167-202.

Miller, G. A., Galanter, E., \& Pribram, K. H. (1960). Plans and structure of behavior. New York: Holt, Rinehart \& Winston.

Neill, W. T., \& Valdes, L. A. (1992). Persistence of negative priming: Steady state or decay? Journal of Experimental Psychology: Learning, Memory, and Cognition, 18, 565-576.

Neill, W. T., Valdes, L. A., Terry, K. M., \& Gorfein, D. S. (1992), Persistence of negative priming: II. Evidence for episodic trace retrieval. Journal of Experimental Psychology: Learning, Memory, and Cognition, 18, 993-1000.

Rabbitt, P. M. A. (1966). Errors and error correction in choice-response tasks. Journal of Experimental Psychology, 71, 264-272.

Ratcliff, R. (1978). A theory of memory retrieval. Psychological Review, $85,59-108$. 
Rieger, M., \& Gauggel, S. (1999). Inhibitory after-effects in the stop signal paradigm. British Journal of Psychology, 90, 509-518.

Rubia, K., Russell, T., Overmeyer, S., Brammer, M. J., Bullmore, E. T., Sharma, T., et al. (2001). Mapping motor inhibition: Conjunctive brain activations across different versions of go/no-go and stop tasks. Neuroimage, 13, 250-261.

Schachar, R. J., Chen, S., Logan, G. D., Ornstein, T. J., Crosbie, J., Ickowicz, A., et al. (2004). Evidence for an error monitoring deficit in attention deficit hyperactivity disorder. Journal of Abnormal Child Psychology, 32, 285-293.

Shiffrin, R. M., \& Schneider, W. (1977). Controlled and automatic human information processing: II. Perceptual learning, automatic attending, and a general theory. Psychological Review, 84, 127-190.

Skinner, B. F. (1938). The behavior of organisms. New York: AppletonCentury-Crofts.

Stevens, M., Lammertyn, J., Verbruggen, F., \& Vandierendonck, A. (2006). Tscope: A C library for programming cognitive experiments on the MS Windows platform. Behavior Research Methods, 38, 280-286.

Tipper, S. P., Grison, S., \& Kessler, K. (2003). Long-term inhibition of return of attention. Psychological Science, 14, 19-25.

Verbruggen, F., Liefooghe, B., \& Vandierendonck, A. (2005). On the difference between response inhibition and negative priming: Evidence from simple and selective stopping. Psychological Research, 69, 262271.

Verbruggen, F., Logan, G. D., Liefooghe, B. \& Vandierendonck, A. (2008). Short-term aftereffects of response inhibition: Repetition priming or between-trial control adjustments? Journal of Experimental Psychology: Human Perception and Performance, 34, 413-426.

Verbruggen, F., Notebaert, W., Liefooghe, B., \& Vandierendonck, A. (2006). Stimulus- and response-conflict-induced cognitive control in the flanker task. Psychonomic Bulletin \& Review, 13, 328-333.

Vince, M. A. (1948). The intermittency of control movements and the psychological refractory period. British Journal of Psychology, 38, 149157.

Waszak, F., Hommel, B., \& Allport, A. (2003). Task-switching and longterm priming: Role of episodic stimulus-task bindings in task-shift costs. Cognitive Psychology, 46, 361-413.

Received June 29, 2007

Revision received October 14, 2007

Accepted December 20, 2007

\section{New Editors Appointed, 2010-2015}

The Publications and Communications Board of the American Psychological Association announces the appointment of 4 new editors for 6-year terms beginning in 2010. As of January 1, 2009, manuscripts should be directed as follows:

- Psychological Assessment (http://www.apa.org/journals/pas), Cecil R. Reynolds, PhD, Department of Educational Psychology, Texas A\&M University, 704 Harrington Education Center, College Station, TX 77843.

- Journal of Family Psychology (http://www.apa.org/journals/fam), Nadine Kaslow, PhD, Department of Psychiatry and Behavioral Sciences, Grady Health System, 80 Jesse Hill Jr. Drive, SE, Atlanta, GA 30303.

- Journal of Experimental Psychology: Animal Behavior Processes (http://www.apa.org/ journals/xan), Anthony Dickinson, PhD, Department of Experimental Psychology, University of Cambridge, Downing Street, Cambridge CB2 3EB, United Kingdom

- Journal of Personality and Social Psychology: Personality Processes and Individual Differences (http://www.apa.org/journals/psp), Laura A. King, PhD, Department of Psychological Sciences, University of Missouri, McAlester Hall, Columbia, MO 65211.

Electronic manuscript submission: As of January 1, 2009, manuscripts should be submitted electronically via the journal's Manuscript Submission Portal (see the website listed above with each journal title).

Manuscript submission patterns make the precise date of completion of the 2009 volumes uncertain. Current editors, Milton E. Strauss, PhD, Anne E. Kazak, PhD, Nicholas Mackintosh, $\mathrm{PhD}$, and Charles $\mathrm{S}$. Carver, $\mathrm{PhD}$, will receive and consider manuscripts through December 31, 2008. Should 2009 volumes be completed before that date, manuscripts will be redirected to the new editors for consideration in 2010 volumes. 